\title{
Evaluation of Hemodynamic Behavior of a Stentless Aortic Bioprosthesis under Stress by Exercise Echocardiography
}

\section{Guglielmo Stefanelli ${ }^{1 *}$, Fabrizio Pirro ${ }^{1}$, Andrea Macchione ${ }^{1}$, Gianpiero Patrizi ${ }^{1}$, Luca Weltert ${ }^{2}$ and Andrea Barbieri ${ }^{3}$}

${ }^{1}$ Department of Cardiology and Cardiac Surgery, Hesperia Hospital, Modena, Italy

${ }^{2}$ Department of Cardiac Surgery, European Hospital, Rome, Italy

${ }^{3}$ Department of Cardiology, University Hospitals, Modena, Italy

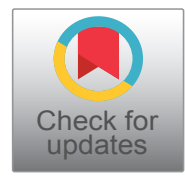

*Corresponding author: Guglielmo Stefanelli, Department of Cardiology and Cardiac Surgery, Hesperia Hospital, via Arquà 80, Modena (IT), Italy, Tel: +39-059449259; +39-3296326970

\begin{abstract}
Background: Aim of this study was to evaluate by transthoracic echo the hemodynamic behaviour and the changes in dimensional data of a stentless aortic bioprosthesis between rest and exercise conditions.

Methods: 254 patients affected by stenosis or stenoinsufficiency of the aortic valve received a Sorin Pericarbon Freedom (SPF) aortic bioprosthesis at our institution between 2003 and 2010. Out of the entire cohort, 184 patients, alive and capable of sustaining an exercise test 7 years after surgery, were selected and enrolled in the study (mean age: $69.7 \pm 10.9$ years, $51.6 \%$ male, mean EF: $53.0 \pm 7.1$ ). All patients were evaluated by transthoracic echocardiography in order to assess hemodynamics at the time of hospital discharge and after 7 years. Followup control consisted of clinical examination and rest and exercise echocardiographic evaluation using a semisupine bicycle with a workload of $25 \mathrm{~W}$ every two minutes, increasing up to $100 \mathrm{~W}$.
\end{abstract}

Results: Comparing rest to exercise, mean gradient increased from $7.8 \pm 3.3 \mathrm{mmHg}$ to $11.6 \pm 4.0 \mathrm{mmHg}$ ( $p<$ 0.05 ) and peak gradient from $14.9 \pm 5.2 \mathrm{mmHg}$ to $21.6 \pm$ $6.5 \mathrm{mmHg}(p<0.05)$ at maximum stress, without significant differences between valve sizes. Concurrently EOA and EOAi raised from $1.86 \pm 0.69 \mathrm{~cm}^{2}$ to $1.96 \pm 0.71 \mathrm{~cm}^{2}$ (p $<0.0001)$, and from $1.05 \pm 0.37 \mathrm{~cm}^{2}$ to $1.10 \pm 0.38 \mathrm{~cm}^{2}$ $(p<0.0001)$ respectively, without significant differences between the implanted valve sizes. Intraaortic regurgitation was absent or trivial in $98 \%$ of patients, and did not change with exercise.
Conclusions: Use of exercise echocardiography to assess changes in hemodynamics and function of aortic bioprostheses can be helpful in the choice of appropriate aortic valve substitutes. SPF pericardial stentless valve presents favourable and durable hemodynamic characteristics at rest and on exercise, similar to native aortic valve. This prosthesis maybe suitable for patients with small aortic annulus and large BSA to avoid mismatch.

\section{Keywords}

Aortic valve replacement, Stentless prosthesis, Exercise Echocardiographic evaluation

\section{Introduction}

Echocardiography is the method of choice for evaluating prosthetic valve function. In almost all the studies reporting early and long-term results after aortic valve replacement with a biological substitute, conclusions regarding valve performances are mainly based on echocardiographic examination at rest. Anyway, is well known that normally and abnormally functioning prostheses can give similar gradients at rest evaluation. Therefore echocardiographic examination after exercise can be very helpful in assessing changes in valve hemodynamics, ventricular function and clinical status under stress conditions.

Most prosthetic aortic valves are inherently stenotic, and particularly for small sizes, a moderate or severe patient-prosthetic mismatch (PPM) may be occasional-

Citation: Stefanelli G, Pirro F, Macchione A, Patrizi G, Weltert L, et al. (2018) Evaluation of Hemodynamic Behavior of a Stentless Aortic Bioprosthesis under Stress by Exercise Echocardiography. Int J Clin Cardiol 5:132. doi.org/10.23937/2378-2951/1410132

Accepted: December 20, 2018; Published: December 22, 2018

Copyright: (c) 2018 Stefanelli G, et al. This is an open-access article distributed under the terms of the Creative Commons Attribution License, which permits unrestricted use, distribution, and reproduction in any medium, provided the original author and source are credited. 
ly present, particularly in patients with large body size. PPM is a frequent cause of increased transprosthetic gradients and leads to poor results after aortic valve replacement. Impaired exercise capacity, incomplete or limited regression of left ventricular hypertrophy, pulmonary hypertension and increased cardiac events and mortality are the results of severe PPM after prosthetic aortic replacement. The presence of same degree of PPM should always be suspected in patients whose symptomatic status is discordant with valve function evaluated at rest. Stentless aortic valves have shown in most experiences excellent hemodynamic behavior, with performances similar to native valve. In this study we aimed to observe the hemodynamic and dimensional data changes of SPF stentless prosthesis occurring between rest and stress conditions.

\section{Methods}

This study concerns a cohort of 184 patients out of 254 , affected by aortic valve stenosis or mixed lesion, who received a SPF at our institution between 2003 and

Table 1: Demographic and clinical characteristics of patients $(n=184)$.

\begin{tabular}{|c|c|c|c|c|}
\hline & $\mathbf{N}$ & $\%$ & $\begin{array}{l}\text { Mean } \pm \text { Std } \\
\text { Dev }\end{array}$ & Range \\
\hline Total & 184 & 73.3 & - & \\
\hline Age [years] & 184 & & $69.7 \pm 10.9$ & $17-85$ \\
\hline$<50$ & 12 & 6.5 & $40.9 \pm 9.5$ & \\
\hline $50-59$ & 15 & 8.3 & $56.4 \pm 3.0$ & \\
\hline $60-69$ & 54 & 29.3 & $66.2 \pm 2.8$ & \\
\hline $70-79$ & 77 & 41.8 & $75.0 \pm 2.7$ & \\
\hline$\geq 80$ & 26 & 14.1 & $82.2 \pm 1.6$ & \\
\hline \multicolumn{5}{|l|}{ Gender } \\
\hline Male & 95 & 51.6 & - & \\
\hline Female & 89 & 48.4 & - & \\
\hline $\mathrm{BSA}[\mathrm{m} 2]$ & 184 & & $1.78 \pm 0.20$ & $1.29-2.26$ \\
\hline \multicolumn{5}{|l|}{ Euroscore } \\
\hline Linear & 184 & & $6.39 \pm 2.55$ & $1.00-14.00$ \\
\hline Logistic & 184 & & $7.73 \pm 7.09$ & $1.23-43.17$ \\
\hline \multicolumn{5}{|c|}{ Preoperative NYHA class } \\
\hline I & 41 & 22.3 & - & - \\
\hline II & 83 & 45.1 & - & - \\
\hline III & 57 & 31.0 & - & - \\
\hline IV & 3 & 1.6 & - & - \\
\hline \multicolumn{5}{|c|}{ Aortic valve pathology } \\
\hline Stenosis & 97 & 52.7 & - & - \\
\hline Insufficiency & 42 & 22.8 & - & - \\
\hline Steno-insufficiency & 45 & 24.5 & - & - \\
\hline \multicolumn{5}{|l|}{ Etiology a } \\
\hline Degenerative & 115 & 62.5 & - & - \\
\hline Rheumatic & 61 & 33.2 & - & - \\
\hline$A B E$ & 10 & 5.4 & - & - \\
\hline Native & 5 & 2.7 & - & - \\
\hline Prosthesis & 5 & 2.7 & - & - \\
\hline Peri-aortic abscess & 5 & 2.7 & - & - \\
\hline EF ejection fraction & 184 & & $53.0 \pm 7.1$ & $20.0-65.0$ \\
\hline IVS Thickness & 184 & & $14.2 \pm 3.1$ & $8.0-29.0$ \\
\hline
\end{tabular}

ABE: Acute bacterial endocarditis; BSA: Body surface area; EF: Ejection fraction; IVS: Interventricular septum; NYHA: New York Heart Association.
2010. Mean pre-operative gradient was $>40 \mathrm{mmHg}$ and EOA $<0.9 \mathrm{~cm}^{2}$ in all cases of aortic stenosis. The retrospective-design study inclusion criteria were the alive status and the capability to undergo an exercise test at 7 years follow-up control. Hesperia Hospital Institutional Review Board and Scientific Committee approved this study, and individual consent for inclusion in the study was obtained by all patients.

The age of patients ranged between 17 and 84 years (mean age $69.7 \pm 10.9$ ). $44 \%$ of patients were younger than 60 years, $51.6 \%$ were male. Mean Logistic Euroscore was $7.73 \pm 7.09$. 33\% of patients were in NYHA (New York Class Association) class III or IV before surgery. Etiology was degenerative or rheumatic in $96 \%$ of cases. Mean LVEF (Left Ventricular Ejection Fraction) was $53.0 \pm 7.1 \%$ (range $20.0 \%-65.0 \%$ ). Demographic and clinical characteristics of patients are listed in Table 1.

SPF is a pure stentless valve made by two sheets of bovine pericardium. It is a user-friendly device, with the possibility of trimming the inflow and outflow pericardium according to the anatomy of the patient. In all cases the operation was conducted by the same surgeon using cardiopulmonary bypass, aortic crossclamping and cold crystalloid myocardial protection.

Table 2: Surgical characteristics of patients $(n=184)$.

\begin{tabular}{|c|c|c|c|c|}
\hline & $\mathbf{N}$ & $\%$ & $\begin{array}{l}\text { Mean } \pm \text { Std } \\
\text { Dev }\end{array}$ & Range \\
\hline Total & 184 & 73.3 & - & \\
\hline \multicolumn{5}{|l|}{ Emergency } \\
\hline Urgent & 1 & 0.5 & - & \\
\hline Elective & 183 & 99.5 & - & \\
\hline Redo & 8 & 4.4 & - & \\
\hline \multicolumn{5}{|l|}{ Valve size implanted } \\
\hline $\mathrm{n} 19$ & 3 & 1.6 & - & \\
\hline $\mathrm{n} 21$ & 17 & 9.2 & - & \\
\hline $\mathrm{n} 23$ & 45 & 24.5 & - & \\
\hline n25 & 41 & 22.3 & - & \\
\hline n27 & 37 & 20.1 & - & \\
\hline $\mathrm{n} 29$ & 41 & 22.3 & - & \\
\hline \multicolumn{5}{|l|}{$\begin{array}{l}\text { Associated surgical } \\
\text { procedures }^{a}\end{array}$} \\
\hline CABG & 49 & 26.6 & - & \\
\hline $\begin{array}{l}\text { Ascending aorta vasc. } \\
\text { prosthesis }\end{array}$ & 10 & 5.4 & - & \\
\hline Mitral valve & 24 & 13.0 & - & \\
\hline ECC time [min] & 184 & & $120.2 \pm 23.8$ & $80-202$ \\
\hline $\begin{array}{l}\text { Patients with concomitant } \\
\text { procedures }\end{array}$ & 76 & 41.3 & $138.3 \pm 20.8$ & $101-202$ \\
\hline $\begin{array}{l}\text { Patients without } \\
\text { concomitant procedures }\end{array}$ & 108 & 58.7 & $107.5 \pm 16.4$ & $80-167$ \\
\hline $\begin{array}{l}\text { Aortic cross-clamp time } \\
\text { [min] }\end{array}$ & 184 & & $89.3 \pm 16.4$ & $61-158$ \\
\hline $\begin{array}{l}\text { Patients with concomitant } \\
\text { procedures }\end{array}$ & 76 & 41.3 & $91.2 \pm 18.7$ & $61-158$ \\
\hline $\begin{array}{l}\text { Patients without } \\
\text { concomitant procedures }\end{array}$ & 108 & 58.7 & $88.0 \pm 14.4$ & $62-146$ \\
\hline
\end{tabular}

CABG: Coronary artery bypass graft; ECC: Extracorporeal circulation. 
In 8 cases the patients had undergone a previous cardiac operation. Associated surgical procedure were carried out in $45 \%$ of cases. The valve implanted were in $65 \%$ of patients of size greater than 25 . Only $10.8 \%$ of patients received an implant $21(9.2 \%)$ or $19(1.6 \%)$. Surgical characteristics of patients are illustrated in Table 2.

For patients evaluation we preferred a symptomlimited exercise test because is closed to physiology if compared to dobutamine-stress test and may be performed in safe conditions.

A semi-supine exercise bicycle was chosen, due to the reduced risk of haemodynamic collapse of the patient in this position. Besides, the exercise in semisupine position allows a continuous echocardiographic examination. All evaluations were conducted in the hospital echo-lab, appropriately equipped in order to treat possible complications. The workload started at $25 \mathrm{~W}$, and increased by $25 \mathrm{~W}$ every 2 minutes up to a maximum of $100 \mathrm{~W}$. Measurements were obtained by echo during the last two minutes of final step of workload. The test was interrupted earlier in case of onset of symptoms. Blood pressure was measured noninvasively at the basal level and at each workload step. ECG and heart rate were observed in a continuous way by means of a 6 leads monitor. The test were conducted in a controlled environment, in order to treat potential major complications.
All examinations were carried out by a single cardiologist, using the same equipment (Philips HD11XE), in order to avoid possible biases in the analysis. The site of optimal probe position on the chest was marked before the test, in order to obtain the best Doppler waveform.

Mean transprosthetic gradient and peak transprosthetic gradient were measured at rest and at maximum exercise using the modified Bernoulli equation, taking care to obtain the highest possible velocity by variation of the acoustic window and transducer orientation.

Effective orifice area and indexed effective orifice area were calculated using the AVA-Continuity Equation using $\mathrm{VTI}$ at rest and at maximum exercise.

Variations of intra-valvular or peri-valvular regurgitation under exercise were quantified by color-doppler echocardiography.

Analysis of left ventricular function, EF and change of interventricular septum thickness between hospital discharge and at 7 years follow-up were assessed in the short axis of a parasternal view.

The statistical analysis was performed using SPSS (Release 20 IBM Corporation, Armonk, New York, USA) and MedCalc 14.8 (MedCalc Software bvba, Ostend, Belgium).
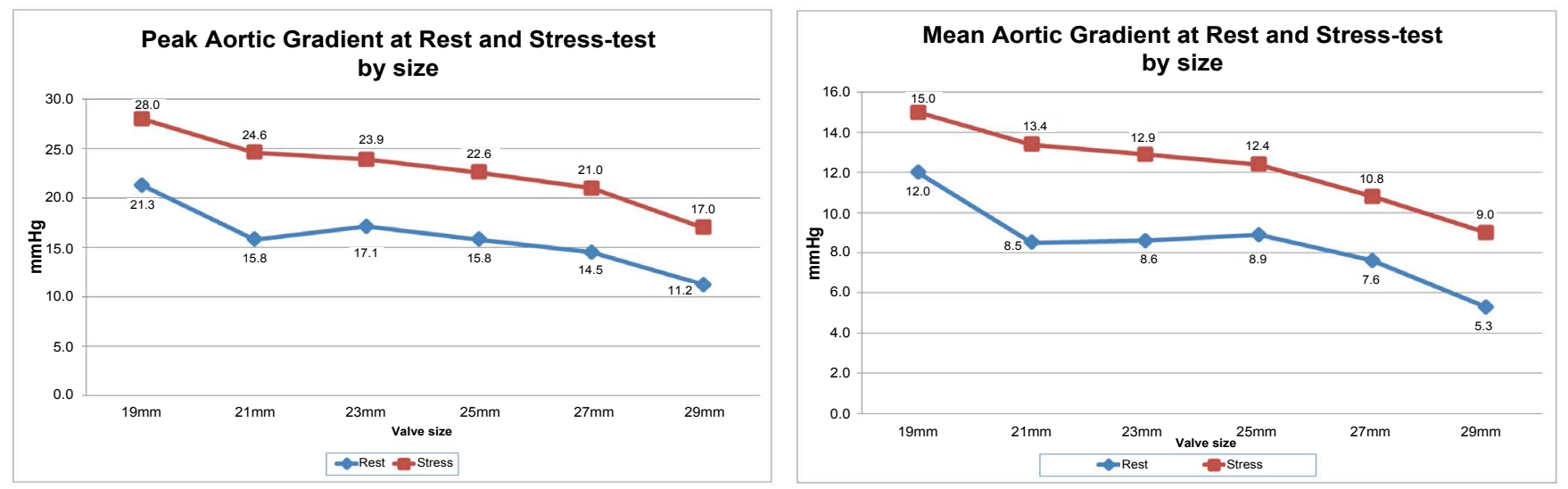

Figure 1: Change of Peak and Mean Transvalvular Gradient After Maximum Stress by Valve Implant Size.

Table 3: Summary of echocardiographic data of patients $(n=184)$.

\begin{tabular}{|l|l|l|l|l|l|}
\hline & Rest & \multicolumn{3}{l|}{ Stress } & \multicolumn{2}{l|}{ p-value } \\
\hline & N & Mean \pm SD & N & Mean \pm SD \\
\hline Mean transvalvular gradient $[\mathrm{mmHg}]$ & 184 & $7.8 \pm 3.3$ & 184 & $11.6 \pm 4.0$ & $<0.0001$ \\
\hline Peak transvalvular gradient $[\mathrm{mmHg}]$ & 184 & $14.9 \pm 5.2$ & 184 & $21.6 \pm 6.5$ & $<0.0001$ \\
\hline EOA $\left[\mathrm{cm}^{2}\right]$ & 184 & $1.86 \pm 0.69$ & 184 & $1.96 \pm 0.71$ & $<0.0001$ \\
\hline EOA index $\left[\mathrm{cm}^{2} / \mathrm{m}^{2}\right]$ & 184 & $1.05 \pm 0.37$ & 184 & $1.10 \pm 0.38$ & $<0.0001$ \\
\hline EF change & 184 & $57 \% \pm 7 \%$ & 184 & $59 \% \pm 7.5 \%$ & 0.0230 \\
\hline & & & & & \\
\hline Intra-aortic regurgitation & $\mathrm{N}$ & $\%$ & $\mathrm{~N}$ & $\%$ & \\
\hline 0 & 184 & & 184 & & \\
\hline 1 & 164 & 89.1 & 161 & 87.5 \\
\hline 2 & 19 & 10.3 & 21 & 11.4 \\
\hline
\end{tabular}

EF: Ejection fraction; EOA: Effective orifice area. 
Data collection was carried out on institutional database registry at time of discharge and reported on Microsoft Excel 2015 datasheets at the time of Echo Stress Control.

All variables specified that described demographic and other characteristics were summarized by means of descriptive statistics, absolute number and percentage was used for discrete variables while mean and standard deviation, as well as range, was used for continuous variables. Two tailed eteroschedastic $T$ test for paired variables was used to verify differences in term of gradients, EOA and EOAi, either overall and with valve size stratification. Scatter plots with interpolation line by logarithmic function was used to graphically describe the findings. A significance level of 0.05 was used as threshold.

\section{Results}

All patients were in NYHA Class I or II at the time of exercise test echocardiographic evaluation. Compared to hospital discharge, Ejection fraction at 7 years followup increased from $53.52 \% \pm 6.9 \%$ to $57.02 \% \pm 7.2 \%$. Thickness of interventricular septum decreased from $14.04 \pm 2.99 \mathrm{~mm}$ to $13.13 \pm 1.65 \mathrm{~mm}$ ( $p: 0.00001$ ). The exercise test was completed by all the patients included in the study. The continuous ECG monitoring did not show any sign of threatening arrhythmias or significant ST changes.

At 7 years follow-up Mean transvalvular gradient increased from $7.8 \pm 3.3 \mathrm{mmHg}$ measured at rest to $11.6 \pm 4.0 \mathrm{mmHg}$ after maximum exercise for the entire cohort, giving a $\Delta$ difference of $3.81 \pm 1.946 \mathrm{mmHg}$ (2 $\mathrm{mmHg}-18 \mathrm{mmHg}$ ). Peak gradient increased $14.9 \pm 5.2$ $\mathrm{mmHg}$ to $21.6 \pm 6.5 \mathrm{mmHg}$ at maximum exercise, giving a $\Delta$ difference of $6.71 \pm 2.72 \mathrm{mmHg}(0 \mathrm{mmHg}-17 \mathrm{mmHg})$. Mean and Peak gradient did not show significant difference as regard to the implanted valve size (Figure 1). Summary of Echocardiographic data before and after Exercise Test are reported in Table 3 and Table 4.

Intra-prosthetic regurgitation did not change significantly after maximum exercise. It was absent or trivial in the majority of patients. Only one patient developed a mild-to moderate incompetence, may be related to an enlargement of the aortic root with pressure increase at maximum exercise. Summary of intra-prosthetic regurgitation data is illustrated in Table 3.

Unlike gradients, EOA (Effective Orifice Area) provides an accurate assessment of severity of the stenosis independent of flow in most hemodynamic conditions. Interestingly EOA and Effective Orifice Area Index (EOAi) increased with exercise. EOA increased from $1.86 \pm 0.69 \mathrm{~cm}^{2}$ before exercise to $1.96 \pm 0.71$ to maximum stress $(p<0.0001)$. EOAi increased from 1.05 $\pm 0.37 \mathrm{~cm}^{2}$ to $1.10 \pm 0.38 \mathrm{~cm}^{2}(\mathrm{p}<0.0001)$. This may be related to the capability of this prosthesis to adapt to different conditions of cardiac output. Variations in EOA and EOA index after exercise were similar for different implanted valve sizes (Figure 2).

Figure 3 shows the mean transprosthetic gradients at rest and during physical exercise as a function of the indexed effective orifice area (EOAi), demonstrating

Table 4: Summary of echocardiographic data of patients according to valve size $(n=184)$.

\begin{tabular}{|c|c|c|c|c|c|}
\hline \multirow[t]{2}{*}{ Parameter } & \multirow[t]{2}{*}{ Valve size } & \multicolumn{2}{|c|}{ Rest } & ST & \multirow{2}{*}{\begin{tabular}{|l|} 
P-value \\
0.0310
\end{tabular}} \\
\hline & & $\mathbf{N}$ & Mean \pm SD & Mean \pm SD & \\
\hline \multirow[t]{6}{*}{ Peak transvalvular gradient [mmHg] } & $19 \mathrm{~mm}$ & 3 & $21.3 \pm 6.0$ & $28.0 \pm 8.0$ & $<0.0001$ \\
\hline & $21 \mathrm{~mm}$ & 17 & $15.8 \pm 3.8$ & $24.6 \pm 3.3$ & $<0.0001$ \\
\hline & $23 \mathrm{~mm}$ & 45 & $17.1 \pm 3.5$ & $23.9 \pm 5.1$ & $<0.0001$ \\
\hline & $25 \mathrm{~mm}$ & 41 & $15.8 \pm 5.3$ & $22.6 \pm 6.6$ & $<0.0001$ \\
\hline & $27 \mathrm{~mm}$ & 37 & $14.5 \pm 7.0$ & $21.0 \pm 8.4$ & $<0.0001$ \\
\hline & $29 \mathrm{~mm}$ & 41 & $11.2 \pm 2.8$ & $17.0 \pm 3.8$ & 0.0351 \\
\hline \multirow[t]{6}{*}{ Mean transvalvular gradient [mmHg] } & $19 \mathrm{~mm}$ & 3 & $12.0 \pm 3.6$ & $15.0 \pm 4.6$ & $<0.0001$ \\
\hline & $21 \mathrm{~mm}$ & 17 & $8.5 \pm 3.0$ & $13.4 \pm 2.4$ & $<0.0001$ \\
\hline & $23 \mathrm{~mm}$ & 45 & $8.6 \pm 2.1$ & $12.9 \pm 3.2$ & $<0.0001$ \\
\hline & $25 \mathrm{~mm}$ & 41 & $8.9 \pm 3.6$ & $12.4 \pm 4.6$ & $<0.0001$ \\
\hline & $27 \mathrm{~mm}$ & 37 & $7.6 \pm 4.0$ & $10.8 \pm 4.7$ & $<0.0001$ \\
\hline & $29 \mathrm{~mm}$ & 41 & $5.3 \pm 1.6$ & $9.0 \pm 2.2$ & - \\
\hline \multirow[t]{6}{*}{ Effective orifice area $\left[\mathrm{cm}^{2}\right]$} & $19 \mathrm{~mm}$ & 3 & $0.93 \pm 0.06$ & $0.93 \pm 0.06$ & 0.0800 \\
\hline & $21 \mathrm{~mm}$ & 17 & $1.25 \pm 0.17$ & $1.27 \pm 0.19$ & 0.0015 \\
\hline & $23 \mathrm{~mm}$ & 45 & $1.44 \pm 0.41$ & $1.53 \pm 0.46$ & $<0.0001$ \\
\hline & $25 \mathrm{~mm}$ & 41 & $1.83 \pm 0.67$ & $1.94 \pm 0.72$ & 0.0008 \\
\hline & $27 \mathrm{~mm}$ & 37 & $1.97 \pm 0.65$ & $2.11 \pm 0.63$ & 0.0002 \\
\hline & $29 \mathrm{~mm}$ & 41 & $2.58 \pm 0.39$ & $2.68 \pm 0.39$ & - \\
\hline \multirow[t]{6}{*}{ Effective orifice area index $\left[\mathrm{cm}^{2} / \mathrm{m}^{2}\right]$} & $19 \mathrm{~mm}$ & 3 & $0.64 \pm 0.09$ & $0.64 \pm 0.09$ & 0.0816 \\
\hline & $21 \mathrm{~mm}$ & 17 & $0.79 \pm 0.14$ & $0.80 \pm 0.16$ & 0.0030 \\
\hline & $23 \mathrm{~mm}$ & 45 & $0.87 \pm 0.29$ & $0.92 \pm 0.32$ & $<0.0001$ \\
\hline & $25 \mathrm{~mm}$ & 41 & $1.06 \pm 0.40$ & $1.13 \pm 0.43$ & 0.0014 \\
\hline & $27 \mathrm{~mm}$ & 37 & $1.06 \pm 0.35$ & $1.14 \pm 0.34$ & 0.0003 \\
\hline & $29 \mathrm{~mm}$ & 41 & $1.35 \pm 0.26$ & $1.40 \pm 0.26$ & 0.0003 \\
\hline
\end{tabular}



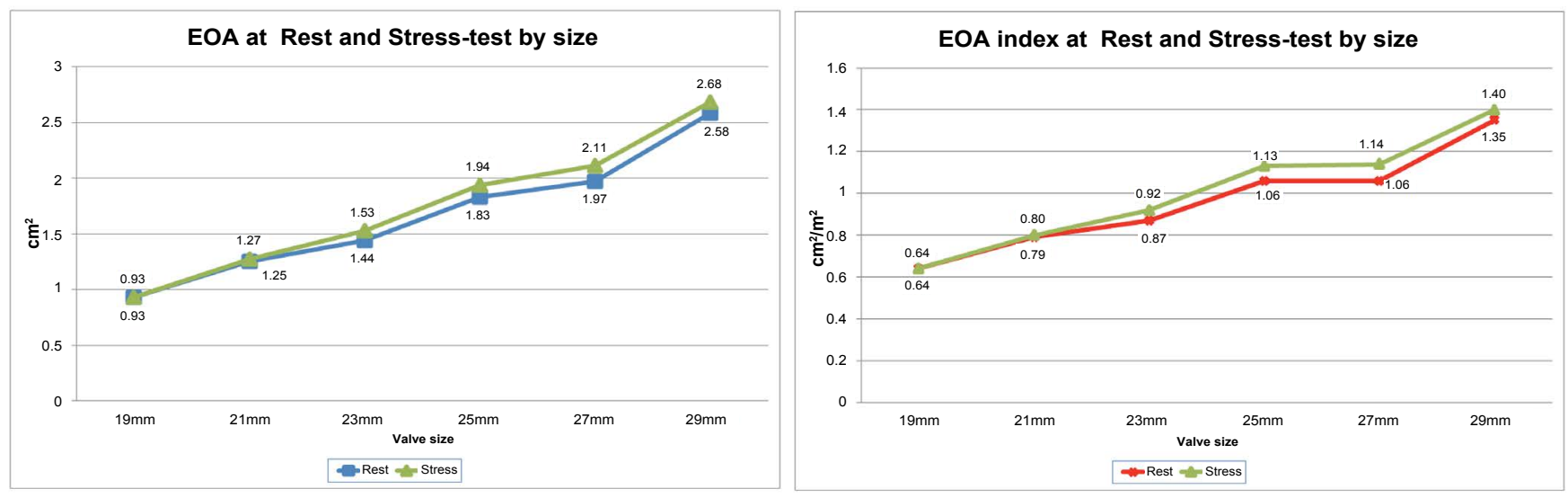

Figure 2: Change of EOA and EOAi After Maximum Stress by Valve Implant Size.
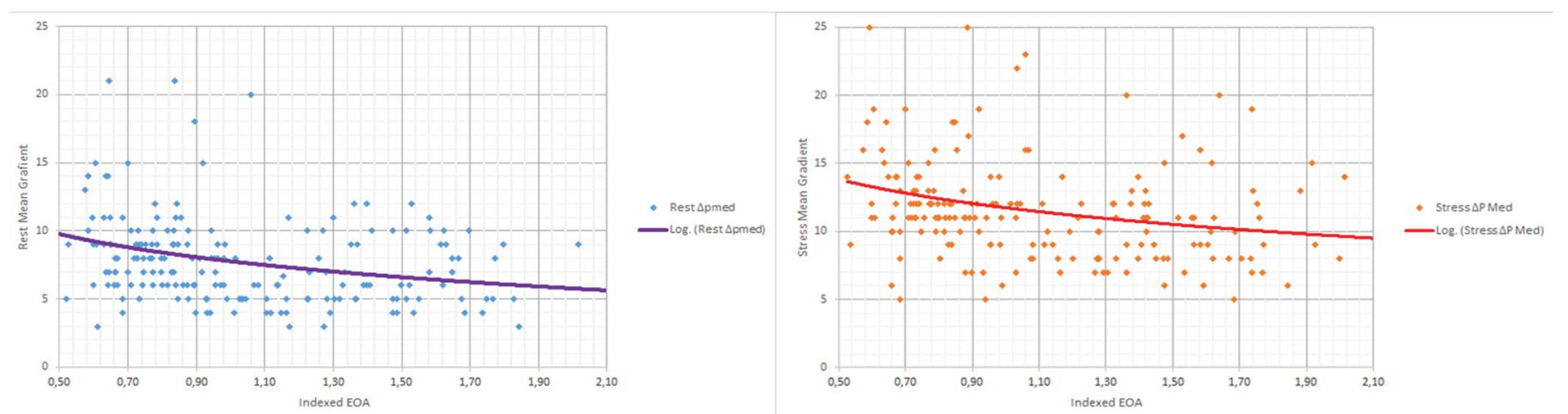

Figure 3: Mean transprosthetic gradients at rest and during physical exercise as a function of the indexed effective orifice area (EOAi).

a fairly linear and low increase in gradient, even at maximum stress.

\section{Discussion}

Doppler Echocardiography is the standardized method of choice for evaluating biological prosthetic aortic valve function [1-3]. It is accurate, non invasive and widely available However, assessment of valve hemodynamic behavior is usually conducted under static conditions. and the subsequent management of possible related abnormalities in valve function and clinical status of the patient relies upon resting evaluation only. Particularly, variations in loading conditions and left ventricular function during a normal patient's activity may lead to significant changes in the severity of lesions. In this setting a more accurate appraisal of valve function can be achieved by an echocardiographic evaluation at rest and under stress conditions. Exercise testing and echocardiography along with dobutamine stress echocardiography are the most frequently used methods to evaluate aortic prostheses.

Exercise test is certainly more physiologic than a dobutamine test; since it can unmask any abnormal exercise capacity and induce symptoms in many patients with apparently normal exercise tolerance. Of course testing should be performed in a controlled environment, in order to treat potential major complications.
We, as recommended by many authors, [4,5] preferred a supine or semi-supine bicycle exercise, essentially because Doppler informations can be obtained at any stage of test, and there is a reduced risk of haemodynamic deterioration.

Exercise is started with a $25 \mathrm{~W}$ workload for 2 minutes, increasing by $25 \mathrm{~W}$ every 2 minutes, up to a maximum of $100 \mathrm{~W}$. Blood pressure, ECG and onset of symptoms are tracked and recorded at every step of workload. Echocardiographic examination is carried on and recorded at rest and at maximum stress, using the standard parasternal long and short axis view and apical 4 and 2 chamber views. The clinical condition of the patient is evaluated and reported.

The standard non-invasive method for assessment of aortic prosthetic function is the evaluation of transvalvular gradients. Estimate of transvalvular gradient is based on the Bernoulli Equation, which defines the relationship between velocity and pressure. While mean pressure gradient is a reliable measure of valve hemodynamics, calculation of peak gradient is usually less precise, being affected by left ventricular contractility in addition to transvalvular flow. Anyway, gradients are sensitive to flow, therefore, for a fixed valve orifice area, gradient increases in a high-flow state and decreases in a reduced-flow state [6].

Calculation of Effective Orifice Area (EOA) is an accurate method of assessment of prosthetic valve 
stenosis since is independent of the flow in any hemodynamic condition. EOA is obtained by Doppler Echocardiography using the continuity equation, and reflects the minimal cross-sectional area of the outflow jet (vena contracta) [7] Valve area must be indexed to body surface area (BSA), obtaining EOAi. Severe valve stenosis is present with a EOA index $<0.6 \mathrm{~cm}^{2} / \mathrm{m}^{2}[2,3]$. Despite EOA is a valid reflection of valve hemodynamics, an exception occurs in cases of very low flow, causing an incomplete valve opening.

Most biological prosthetic aortic valves are inherently stenotic, since the effective orifice area (EOA) maybe too small in relation to body size, thus realizing a condition known as patient-prosthesis mismatch (PPM) $[8,9]$. PPM is moderate when the indexed EOA is $</=$ $0.85 \mathrm{~cm}^{2} / \mathrm{m}^{2}$, severe when it is $</=0.65 \mathrm{~cm}^{2} / \mathrm{m}^{2}$ [10]. PPM is also responsible for increased transprosthetic gradients, often leading to incomplete ventricular mass regression, impaired exercise tolerance, earlier prosthetic degeneration [11,12] and increased rate of cardiac events and short and long-term mortality $[13,14]$, with strong interaction with LV systolic disfunction resulting from LV hypertrophy.

Because normally and abnormally functioning biological aortic valve substitutes can give similar gradients at transthoracic echocardiographic examination at rest, exercise echocardiographic evaluation may be very helpful in revealing the presence of significant PPM, particularly in cases of discordance between the gradient measured at rest and symptomatic status of the patient $[15,16]$. This happens more often with smaller $(</=21 \varnothing)$ aortic biological, mismatched prostheses. An increase in mean transprosthetic gradient $>20 \mathrm{mmHg}$ under exercise, generally indicates severe valve disfunction or Important PPM $[17,18]$ Evaluation of increase in mean gradient is considered more reliable when compared to peak gradient, since the latter is influenced by the left ventricular contractility in addition to the influence of transvalvular flow [19].

Improved hemodynamic performances due to large implant size, suppression of severe patient-prosthesis mismatch associated to earlier regression of left ventricular hypertrophy and increased survival, make of stentless tissue xenografts a reliable solution for aortic valve replacement [20-23], particularly in younger, active population. It has been reported that for a measured annulus size it is possible to implant a stentless prosthesis one or two sizes larger than a stented biological valve [24]. This has been also our experience. Fries, et al. evaluated and compared under exercise stentless and stented aortic valves. They found a behavior similar to native aortic valve for stentless prostheses, while transvalvular gradient increased significantly after exercise in the stented group [25] The Sorin Pericarbon Freedom (SPF) is a true stentless bioprosthesis, present on the market since 1991 and made of two layers of bovine pericardium without any fabric reinforcement. The valve is treated with glutaraldehyde, a subsequent detoxification process with homocysteic is carried out and finally is stored in a aldehyde-free solution, without need for rinsing before implantation [26].

To our knowledge, this is the first study reporting exercise evaluation at intermediate-term follow-up of a large cohort of patients receiving a pericardial stentless valve. The study was designed in order to avoid confounding factors due to the simple assessment of transvalvular gradients. Consequently, an accurate measurement of EOA and EOAi at rest and under exercise was obtained for the entire cohort. All the Echographic examinations were performed by the same cardiologist using the same Echo machine, (Philips HD11XE).

Hemodynamic results of SPF after exercise were excellent, with an increase of mean transvalvular pressure of less than $4 \mathrm{mmHg}$ and an increase of peak gradient of less than $7 \mathrm{mmHg}$, indicating a prosthetic behavior similar to a native valve.

EOA and EOAi, a strong indicator of valve function, increased after maximum exercise by more than $10 \%$, suggesting a possible valve adaption to increased cardiac output.

Concerning the long-term results after aortic valve replacement with SPF bioprosthesis, we have reported in a recent paper the outcomes 14 years after implant of SPF on 322 patients operated in a single institution by a single surgeon between 2003 and 2015 [27]. Overall survival probability at 14 years was $82.7 \%$. Freedom from SVD at 14 years was $88.9 \%$ for patients $>70$ years, $68.2 \%$ in patients younger than 65 . Overall freedom from reoperation at 14 years was $70.3 \%$ for the entire cohort.

Biological valve substitutes are generally unobstructive to flow at resting conditions, but they can become stenotic with increased cardiac output. This is particularly true in case of moderate or severe PPM. Residual aortic stenosis after valve replacement leads to incomplete or absent ventricular mass regression, associated to unfavourable results in terms of early and late mortality and clinical status.

The two main limitations of this analysis are related to the retrospective design of the study and to the absence of a control group. Conversely, all operations were carried out by a single surgeon in a single institution, and all patients received a clinical and echocardiographic evaluation by a single cardiologist, thus avoiding further biases in the analysis.

Exercise echocardiography is growing popularity as a method of choice for evaluation of hemodynamic results after aortic biological valve replacement.

Stentless aortic prostheses have proven to have an hemodynamic behavior similar to native aortic valves $[20,21,23,25]$, and this was confirmed by our experience, They may be a valid option in the case of small aortic 
annulus with substantial risk of severe PPM, and in the young, active population.

\section{Acknowledgements}

The authors wish to thank: Mrs Mara Chiaro, MDV, Mrs Chiara Vieceli, BEng, and Mrs Cristina Limbarino from the Livanova-Sorin Group for their valuable technical assistance.

\section{Potential Conflicts of Interest}

None declared for all authors.

\section{Funding}

No funding was provided for this study.

\section{References}

1. Burstow DJ, Nishimura RA, Bailey KR, Bailey KR, Reeder GS, et al. (1989) Continuous wave Doppler echocardiographic measurement of prosthetic valve gradients: A simultaneous Doppler-catheter correlative study. Circulation 80: 504-514.

2. Bonow RO, Carabello B, Chatterjee $\mathrm{K}$, de Leon AC Jr, Faxon DP, et al. (2006) ACC/AHA 2006 guidelines for the management of valvular heart disease: $A$ report of the American College of Cardiology/American Heart Association Task Force on Practice Guidelines (Writing Committee to Develop Guidelines for the Management of Patients With Valvular Heart Disease) developed in collaboration with the Society of Cardiovascular Anesthesiologists endorsed by the Society for Cardiovascular Angiography and Interventions and the Society of Thoracic Surgeons. J Am Coll Cardiol 48: E1-E148.

3. Vahanian A, Baumgartner H, Bax J, Butchart E, Dion R, et al. (2007) Guidelines on the management of valvular heart disease: the Task Force on the Management of Valvular Heart Disease of the European Society of Cardiology. Eur Heart J 28: 230-268.

4. Sicari R, Niohyannopoulos P, Evangelista A, Kasprzak J, Lancellotti P, et al. (2008) Stress echocardiography consensus statement of the European Association of Echocardiography (EAE) (a registered branch of the ESC). Eur J Echocardiogr 9: 415-437.

5. Pellikka PA, Nagueh SF, Elhendy AA, Kuehl CA, Sawada SG (2007) American Society of Echocardiography recommendations for performance, interpretation, and application of stress echocardiography. J Am Soc Echocardiogr 20: 1021-1041.

6. Hatle L, Angelsen BA, Tomsdal A (1980) Non-invasive assessment of aortic stenosis by Doppler ultrasound. $\mathrm{Br}$ Heart J 43: 284-292.

7. Quinones MA, Otto CM, Stoddard M, Waggoner A, Zoghbi WA (2002) Recommendations for quantification of Doppler echocardiography: a report from the Doppler Quantification Task Force of the Nomenclature and Standards Committee of the American Society of Echocardiography. J Am Soc Echocardiogr 15: 167-184.

8. Rahimtoola SH (1978) The problem of valve prosthesispatient mismatch. Circulation 58: 20-24.

9. Rahimtoola SH (1998) Valve prosthesis-patient mismatch: An update. J Heart Valve Dis 7: 207-210.

10. Pibarot P, Dumesnil JG (2000) Hemodynamic and clinical impact of prosthesis-patient mismatch in the aortic valve and its prevention. J Am Coll Cardiol 36: 1131-1141.

11. Flameng $W$, Herregods $M C$, Vercalsteren $M$, Herijgers P, Bogaerts K, et al. (2010) Prosthesis-patient mismatch predicts structural valve degeneration in bioprosthetic heart valves. Circulation 121: 2123-2129.

12. Urso S, Calderon P, Sadaba R, Mahillo I, Tuñón J, et al. (2014) Patient-prosthesis mismatch in patients undergoing bioprosthetic aortic avalve implantation increases risk of reoperation for structural valve deterioration. J Card Surg 29: $439-444$

13. Rahimtoola SH, Murphy E (1981) Valve prosthesis-patient mismatch: A long-term sequela. Br Heart J 45: 331-335.

14. Bleiziffer S, Eichinger WB, Hettich I, Ruzicka D, Wottke $M$, et al. (2008) Impact of prosthesis-patient mismatch on exercise capacity in patients after bioprosthetic aortic valve replacement. Heart 94: 637-641.

15. Pibarot P, Dumesnil JG, Jobin J, Cartier P, Honos G, et al. (1999) Hemodynamic and physical performance during maximal exercise in patients with an aortic bioprosthetic valve: Comparison of stentless versus stented bioprostheses. J Am Coll Cardiol 34: 1609-1617.

16. Pibarot P, Dumesnil JG, Jobin J, Lemieux M, Honos G, et al. (1999) Usefulness of the indexed effective orifice area at rest in predicting an increase in gradient during maximum exercise in patients with a bioprosthesis in the aortic valve position. Am J Cardiol 83: 542-546.

17. Tatineni S, Barner HB, Pearson AC, Halbe D, Woodruff R, et al. (1989) Rest and exercise evaluation of St. Jude Medical and Medtronic Hall prostheses: influence of primary lesion, valvular type, valvular size, and left ventricular function. Circulation 8: 16-23.

18. Hobson NA, Wilkinson GA, Cooper GJ, Wheeldon NM, Lynch J, et al. (2006) Hemodynamic assessment of mitral mechanical prostheses under high flow conditions: comparison between dynamic exercise and dobutamine stress. J Heart Valve Dis 15: 87-91.

19. Bach DS (2010) Echo/Doppler Evaluation of Hemodynamics After Aortic Valve Replacement Principles of Interrogation and Evaluation of High Gradients Jacc. Cardiovascular Imaging 3: 296-304.

20. David TE, Pollick C, Bos J (1990) Aortic Valve Replacement with Stentless Porcine Aortic Bioprosthesis. J Thorac Cardiovasc Surg 99: 113-118.

21. Chan KM, Rahman-Haley S, Mittal TK, Gavino JA, Dreyfus GD (2011) Truly Stentless Autologous Pericardial Aortic Valve Replacement: An Alternative to Standard AorticValve Replacement. J Thorac Cardiovasc Surg 14: 276-283.

22. Cohen G, Christakis GT, Joyner CD, Morgan CD, Tamariz $M$, et al. (2002) Are Stentless Valves Hemodynamically Superior to Stented Valves? A Prospective Randomized Trial. Ann Thorac Surg 73: 767-775.

23. Kunadian B, Vijayalakshmi K, Thornley AR, de Belder MA, Hunter S, et al. (2007) Meta-analysis of Valve Hemodynamics and Left Ventricular Mass Rregression for Stentless versus Stented Aortic Valves. Ann Thorac Surg 84: 73-78.

24. Silberman S, Shaheen J, Merin O, Fink D, Shapira N, et al. (2001) Exercise Hemodynamics of Aortic Prostheses: Comparison Between Stentless Bioprostheses and Mechanical Valves. Ann Thorac Surg 72: 1217-1221.

25. Fries R, Wendler $O$, Schieffer $H$, Schäfers HJ (2000) Comparative rest and exercise hemodyamics of 23-mm 
stentless versus 23-mm stented aortic bioprostheses. Ann Thorac Surg 69: 817-822.

26. Stacchino C, Bona G, Rinaldi S, Vallana F (1995) Design and performance characteristics of the Pericarbon stentless valve. J Heart Valve Dis 4: S102-S105.
27. Stefanelli G, Pirro F, Olaru A, Danniballe G, Labia C, et al. (2018) Long-term outcomes using the stentless LivaNovaSorin Pericarbon Freedom ${ }^{\mathrm{TM}}$ valve after aortic valve replacement. Interact Cardiovasc Thorac Surg 27: 116-123. 